\title{
On the Modification of Air-mass over the Japan Sea when the Outburst of Cold Air Predominates*
}

\author{
By S. Manabe \\ Geophysical Institute, Tokyo University \\ (Manuscript received 28 Dec., 195\%)
}

\begin{abstract}
Japan Sea is generally considered to be one of the places where the most rapid airmass transformation takes place in winter season. As it is surrounded by the dense network of radiosonde and surface observation stations, quantitative investigation about the modification of airmass is possible. Selecting the period of a typical continuous outburst of cold air from 20 Dec. '54 to 3 Jan. '55 during which the air-sea temperature difference exceeded $10^{\circ} \mathrm{C}$, we computed the integrated netflux divergence of enthalpy and water vapor and the vertical transport of them at the standard levels in the lower half of the troposphere, and further estimated the amount of heating and cooling due to radiation and condensation. Then, based upon the balance requirement, the amount of heat or water vapor supplied from the sea to the atmosphere was obtained. According to the results of above computations, it is concluded that the amount of supplied heat is as much as $1000 \mathrm{ly} / \mathrm{day}$ in such a typical unstable situation, and is 2.3 times as large as that of supplied latent heat in spite of the fact that mean Bowen's ratio expected from mixing length theory was nearly equal, to unity. Finally, for several periods when no remarkable cyclone passed over the Japan Sea, the amount of evaporation computed by the scheme above-mentioned are compared with the results obtained by use of climatological evaporation equation after Jacobs.
\end{abstract}

\section{Introduction}

The study of the modification of airmass over the ocean has been made by many authors. For example, Wexler(16) estimated the worldwide distribution of heat sources and sinks in 1000-700 mb layers from the mean circulation data. Winston, ${ }^{(17)}$ considering the effect of vertical velocity derived from vorticity equation, estimated the degree of airmass transformation when the cold arctic air poured over the Gulf of Alaska and found that the remarkable transformation of airmass took place during this period. Mura$\mathrm{kami}^{(9)}$ also estimated the seasonal variation of the distribution of heat and cold sources over the Far East taking into consideration of the effect of the climatological distribution of vertical velocity obtained by use of avaraged vorticity equation.

On the other hand, based on the heat budget of the ocean, Jacobs ${ }^{(6)}$ dertermind the relation between the amount of energy exchange and meteorological element, computed

* Division of Meteorology, Contribution No. 113. the amount of heat energy and water vapor supplied from the sea to the atmosphere for various seasons, and obtained the results comparable with Wexler's.

In order to obtain a complete understanding about this problem, accurate attack by both meteorologists and oceanographers seems to be necessary. However, one of the main difficulties which meteorologists encounter is the scarcity of data over the ocean. Fortunately, as the Japan Sea is surrounded by Japanese islands, Siberia and Korea, it is enclosed by the network of radio-sonde and many surface observation stations. Furthermore, the degree of airmass modification during the period of the outburst of cold air is especially remarkable due to large air-sea temperature difference as compared with other regions. Therefore this is one of the most suitable places for the investigation of this kind.

As this problem seems to be important both from the standpoint of snowfall prediction over "Back" Japan i.e. north-west cost of the Japanese islands during winter and from that of the forecast of rapid cyclone development 
in this area, several researches have been made on this subject by many authors. For example, Miyazaki ${ }^{(8)}$ investigated the energy budget of the Japan Sea along the line proposed by Jacobs, considering the influence of Tsushima warm current. Arakawa(2), Takahashi(15) and Kurooka ${ }^{(7)}$ described how the airmass was modified during the passage over the Japan Sea and attempted to explain some of the typical observable phenomena.

At the present stage of investigation abovementioned, the present author intends to estimate the amounts of exchange of both sensible heat and latent energy as accurate as possible by using the network of surface and upper air observations, and to extend our discussions to such a kind of problem whether Jacobs' scheme is applicable for the estimation of airmass modification over the Japan Sea or not, or whether heat transfer is to be treated analogously with water vapor transfer or not in such a typical unstable situation.

\section{Outline of the computational procedure}

Since the Japan Sea is enclosed by the comparatively dense network of observation stations, it is possible to obtain the accurate value of net outflow of both enthalpy and water vapor flux by the line integral along the boundary of the sea. On the other hand, the line integral of the observed wind vectors gives us the mean divergence of air and accordingly the mean vertical velocity over the sea from which the mean vertical transport of various quantity is to be computed. Combining these two results, we estimated the heating or the increment of water vapor content at various layers of the air. For the construction of this scheme, the work after Benton and Estoque ${ }^{(3)}$ about the water vapor

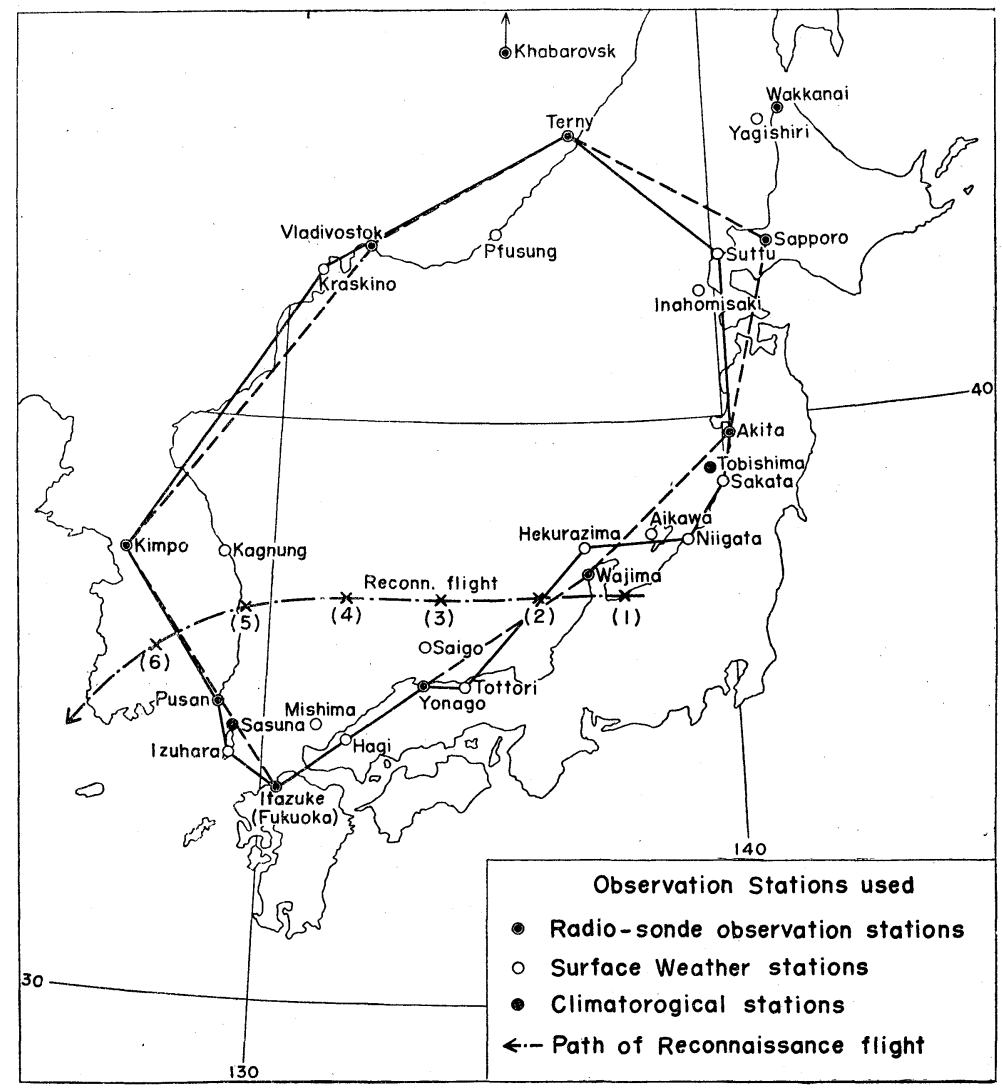

Fig. 1. Network of observation adopted for present calculations. Polygon enclosed by solid line and that enclosed by dotted line show the area for the computation of divergence at surface and at upper levels respectively. Dash-dotted line shows the path of RECCO flight. 
transport over the North American continent was referred.

Furthermore, the heating and cooling due to incoming solar radiation and long wave radiation were calculated by interpolating the values of surrounding radiosonde observation stations, and the heat released by condensation is also estimated by use of the surface precipitation data of islands and coastal regions. Finally, from the balance requirement of heat energy and water vapor, estimation of the amount of both quantities supplied from sea to the atmosphere is performed. Here the work about the North-east trade of the Pacific Ocean after Riehl et al (12) was referred for the computation of radiation.

\section{Network of observation}

The distribution of upper and surface observation stations used is shown in Fig. 1, where the polygon enclosed by solid lines and that enclosed by dotted lines are the domains for the computation of the surface and upper horizontal divergence of airmass respectively. As reference, the height of stations whose observations of surface wind were used for the computation of divergence or for the determination of surface wind velocity are tabulat-

Table 1. List of surface observation stations used for the determination of surface wind vectors.

\begin{tabular}{l|l|r|r}
\hline & & $H(\mathrm{~m})$ & $h_{a}(\mathrm{~m})$ \\
\hline $47-401$ & Wakkani & 1.8 & 13.3 \\
$47-421$ & Suttsu & 15.7 & 11.4 \\
$47-582$ & Akita & 9.1 & 14.1 \\
$47-587$ & Sakata & 2.0 & 14.2 \\
$47-600$ & Wajima & 5.6 & 13.7 \\
$47-601$ & Hekurajima & 12.4 & 8.9 \\
$47-604$ & Niigata & 2.3 & 13.7 \\
$47-746$ & Tottori & 17.3 & 13.5 \\
$47-744$ & Yonago & 6.5 & 19.5 \\
$47-754$ & Hagi & 5.5 & 17.4 \\
$47-804$ & Fukuoka & 2.1 & 19.0 \\
$47-800$ & Izuhara & 20.8 & 11.5 \\
$47-109$ & Pusan & 2 & \\
$47-108$ & Kimp & 20 & \\
$31-967$ & Kraskino & 12 & \\
$31-909$ & Terny & 11 & \\
$31-959$ & Tetiukha & 7 & \\
\hline
\end{tabular}

$H$ : Height of observation station from the sea level. $h_{a}$ : Height of anemometer above the ground. ed in Table 1. Here, we tried to select the low coastal observation stations which are not shielded from northwest wind by the obstacles such as mountains or hills.

In addition, there are daily observations of clouds by RECCO flight by U. S. Air Force which are very useful for the determination of cloud distribution. The path of the flight is also shown in Fig. 1.

\section{General features of the synoptic situa- tion adopted}

During the period selected, i.e. from $03 \mathrm{GCT}$ 20 Dec. '54 to 15 GCT 3 Jan. '55, the continuous outburst of the cold air predominated and no intense cyclone hardly passed over the Japan

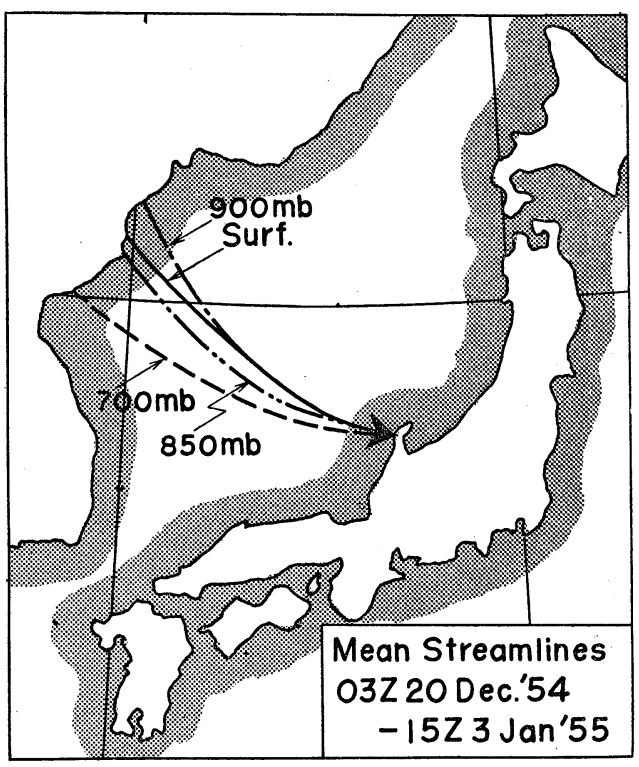

Fig. 2. Mean streamlines of air ariving at Wajima at each standard level.

Sea, though a few weak cyclones passed through the northern boundary of it. Mean streamlines at various standard levels passing over Wajima are shown in Fig. 2 which shows the predominance of northerly or northwesterly flow during this period. The mean isotachs* in Fig. 3 manifest the stronger outburst over the northern half of the Japan Sea. If we compare this distribution with

* This isotaches are decided by interpolating the values of mean wind velocities at the surrunding routine observation stations. As for the heights of observation stations, refer Table 1 . 
the frequencies of the scale of wind wave obtained at various observation stations on the islands off the coast of "Back" Japan (Fig. 4), fairly good correspondence is found out, i.e. the stronger the wind, the more frequently intense wind wave appears.

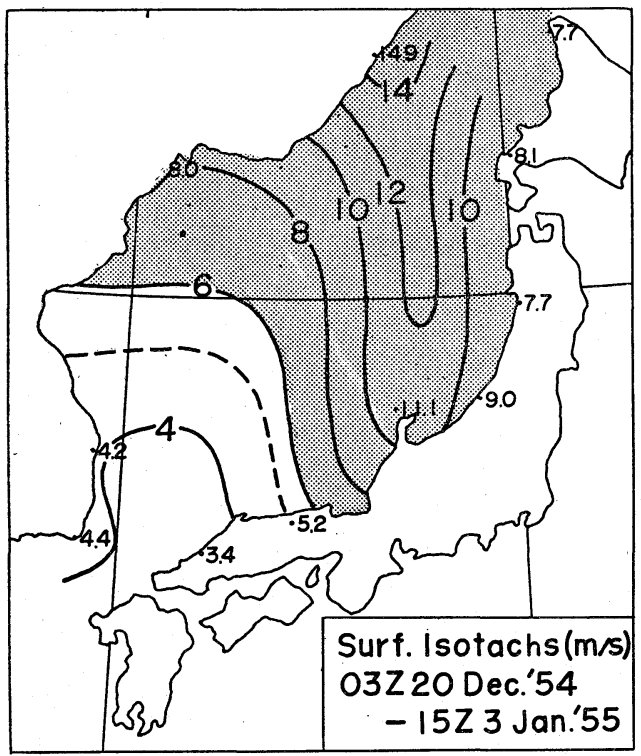

Fig. 3. Mean isotachs at the surface of the Japan Sea. The area where wind speeds exceeded $6 \mathrm{~m} / \mathrm{sec}$ is shaded.

The mean cloud distribution of outgoing side i.e. over the west coast of the Japanese Islands is also shown in Fig. 5b, which is determined by use of daily radiosonde data, visual observation by RECCO flight and surface observation of cloud. As mentioned by many authors, in the sub-cloud layer lapse rate is nearly dry adiabatic, inside the cloud layer it is moist-adiabatic and at the top of cloud weak inversion appears, therefore ascent curve is a good measure for the determination of cloud distribution. In Fig. 5a, the heights of inversion base are plotted for each observation station, where we notice that inversion base is higher over the northern part than over the southern part of "Back" Japan. This tendency may have some connection with the distribution of wind velocity over the Japan Sea (refer Fig. 3). Over the entrance region i.e. the continental side of the Sea there hardly appears cloud, and only the strong inversion is remarkable.
Next, the mean vertical distributions of potential temperature and the mixing ratio of water vapor at the entrance and exit regions of airmass are given in Fig. 6a, 6b respectively. The relative positions of the two cross sections are adjusted referring to the mean

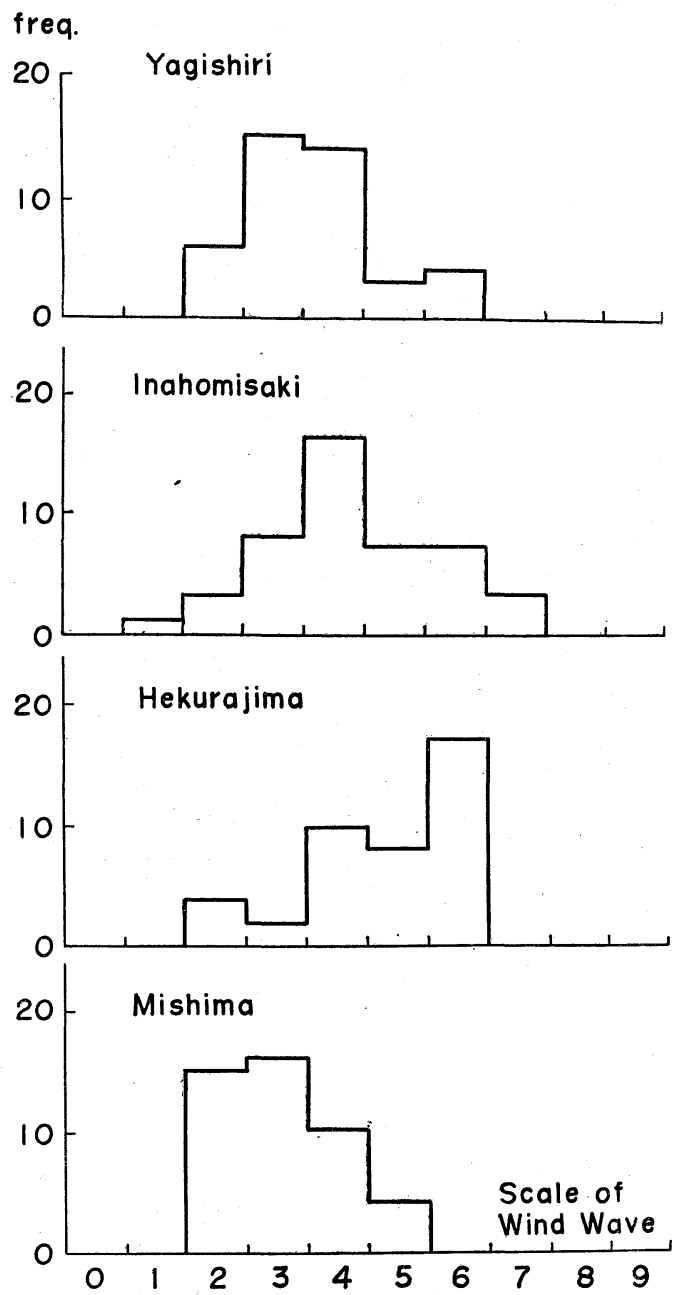

Fig. 4. The frequencies of the scale of wind wave at various observation stations, where observation was made three times a day $(03 \mathrm{GCT}$ 20-15GCT 31 Dec. '54).

stream lines in Fig. 2. Here we notice that the remarkable modification of air took place during the passage over the Japan Sea.

One of the main factors which cause such a rapid modification is the difference between the temperature of sea water and that of the atmosphere. So mean temperature of sea water, mean air-sea difference of temperature 
and mixing ratio of water vapor during this selected period* are shown in Fig. 7 and

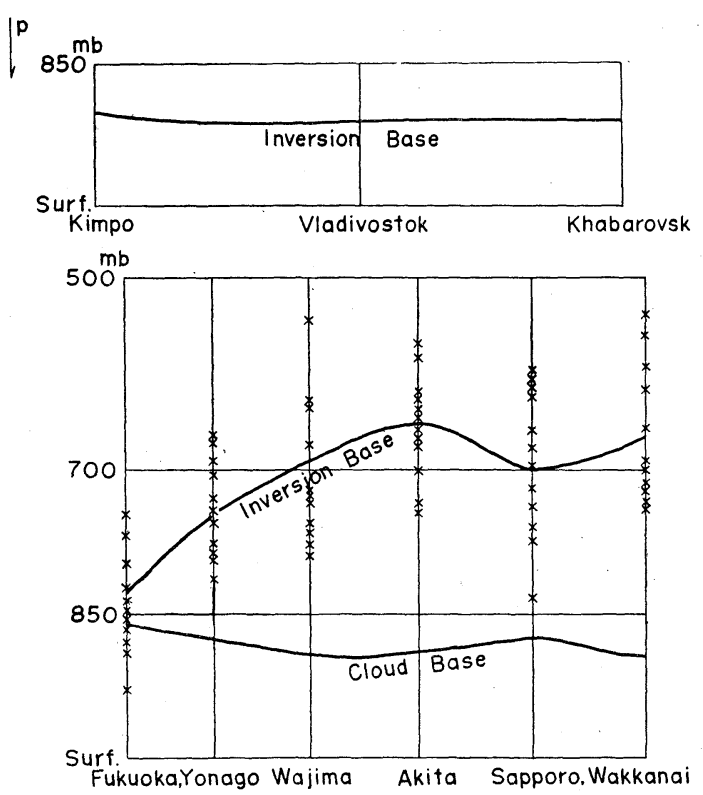

Fig. 5a. Distribution of the height of inversion base over both side of the Japan Sea.

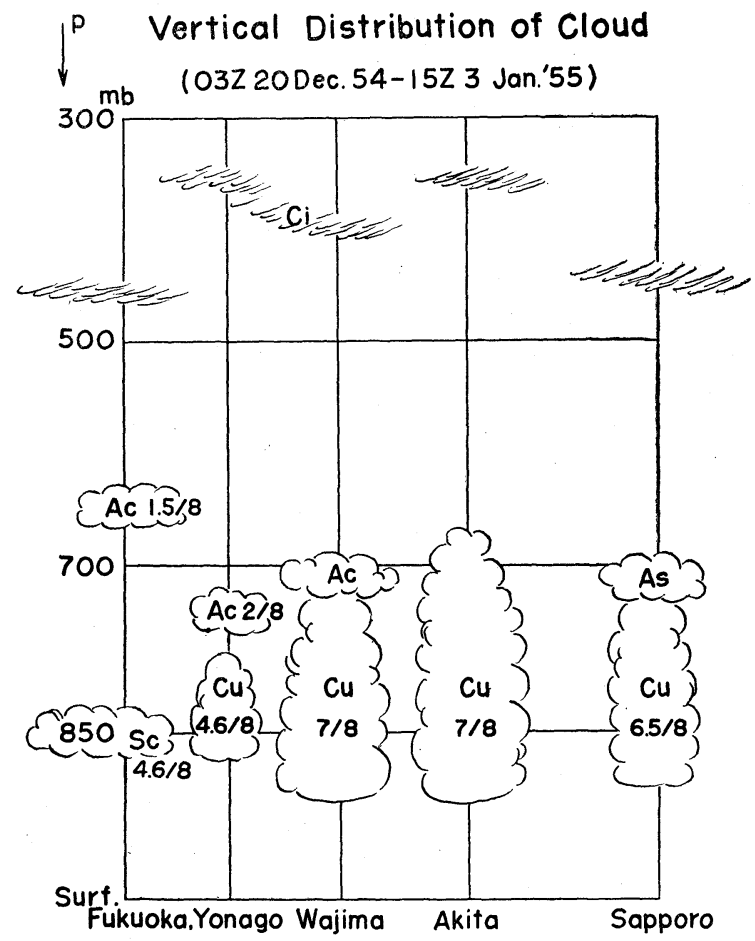

Fig. 5b. Cloud distribution over the west coast of the Japan islands.
Fig. 8a, b respectively, which are constructed based on the first 10 day mean of the sea surface temperature of each month published by the Fishery Institute of Tokai Region. The temperature difference which exceeds $10^{\circ} \mathrm{C}$ suggests the occurrence of intense convection
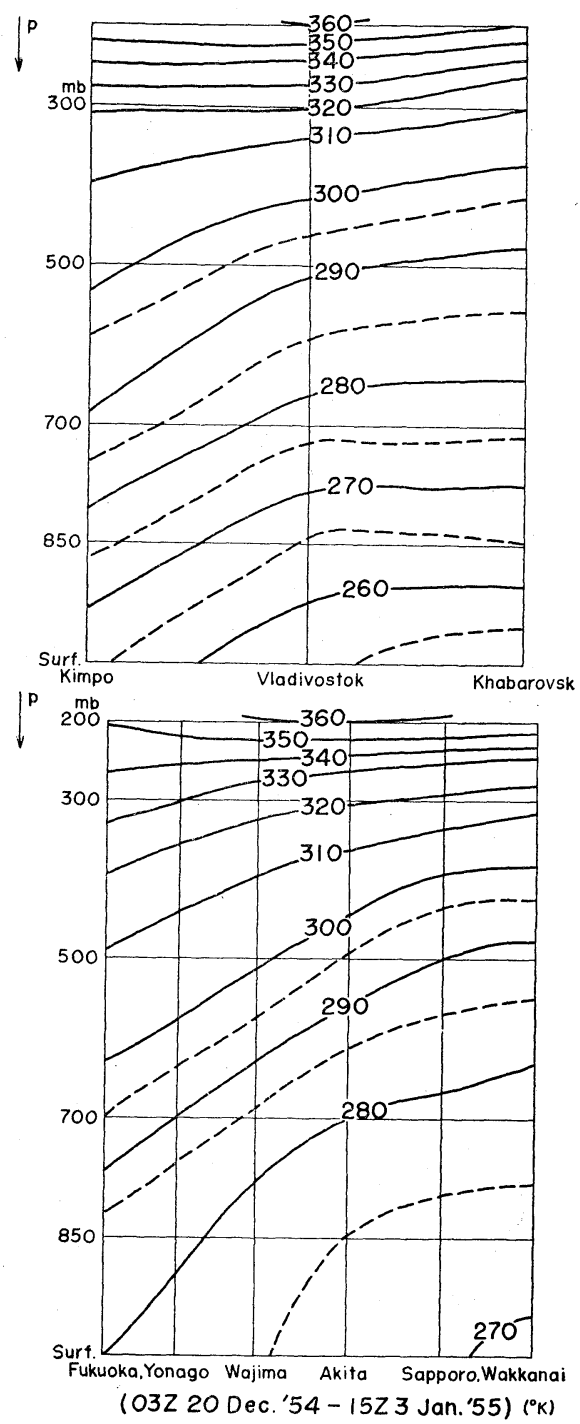

Fig. 6a. Mean vertical distribution of potential temperature before and after the passage of airmass over the Japan Sea.

* Air temperature and mixing ratio of water vapor at the sea surface are obtained by interpolating the values observed at the surrounding surface observation stations and those observed at the light houses on small islands. 


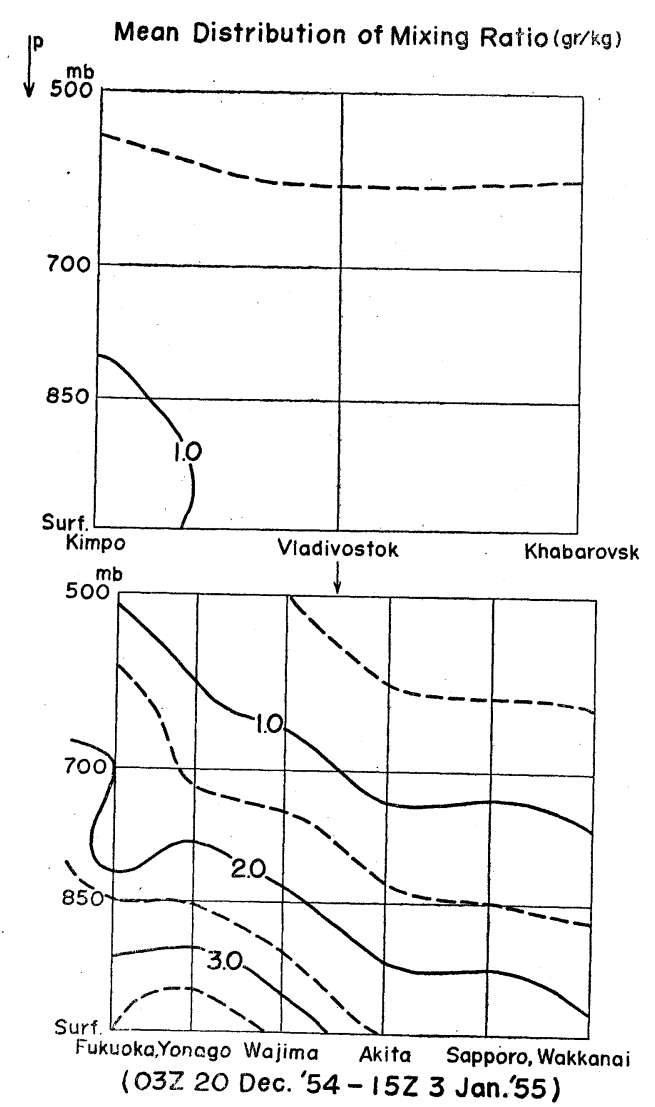

Fig. 6b. Mean vertical distribution of mixing ratio of water vapor per kilogram of air.

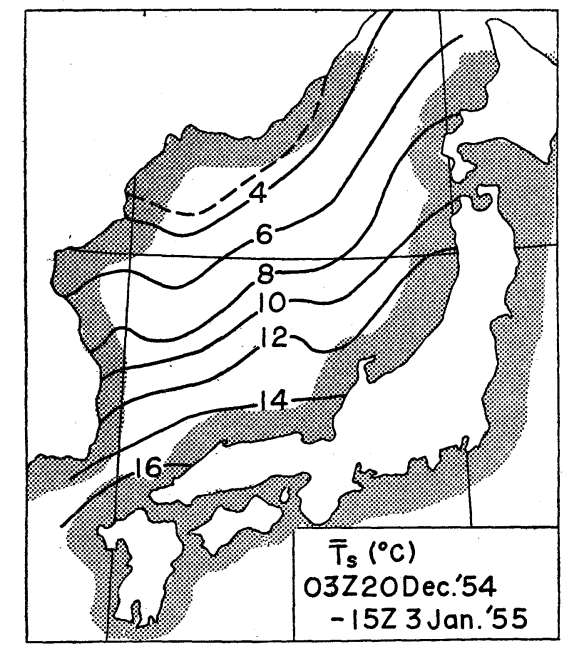

Fig. 7. Mean temperature of surfac sea water which is obtained by use of data published by the fishery institute of Tokai region.

in the lower layer of the atmosphere. As for

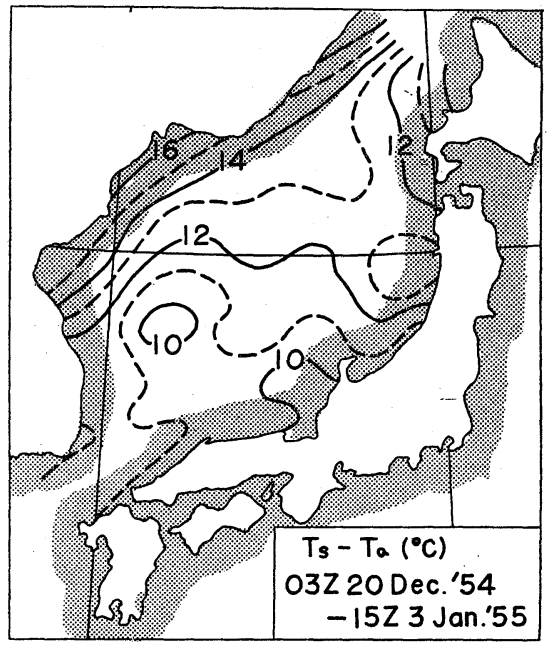

Fig. 8a. The mean temperature difference between the surface air and that of sea water.

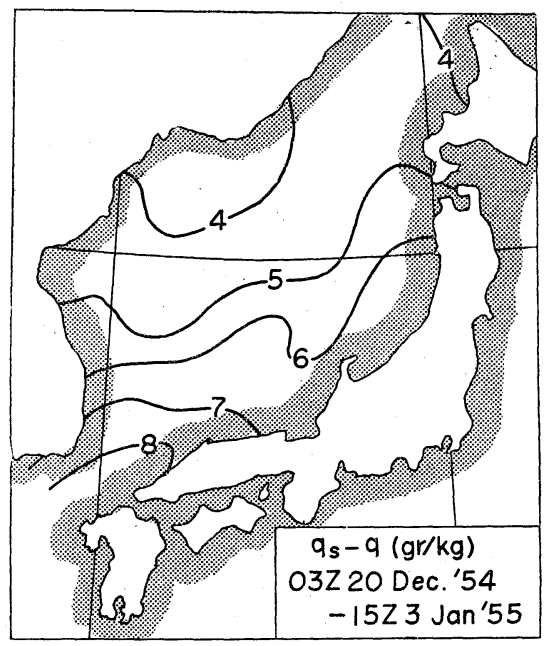

Fig. $8 \mathrm{~b}$. The mean difference between the mixing ratio of water vapor in the air and the saturation mixing ratio for surface sea water.

the cloud distribution in Fig. 5b, under $900 \mathrm{mb}$ level ordinary dry convection and above this level up to $700 \mathrm{mb}$ level moist convection which is excited by condensation seem to predominate.

Finally, the situation under the sea surface must be mentioned. In Fig. 9, one example of the time isopleth of the vertical distribution of sea temperature off the north-west coast of Japan is shown. According to this, during winter temperature is nearly constant from the surface to as deep as $100 \mathrm{~m}$. This fact 
may suggest that the strong convection takes place also in the sea water during this season.

5. Estimation of the amounts of heat and water vapor supplied from the sea to the atmosphere

In this section, along the line outlined in section 2 , detailed explanation of the computation procedure will be made.

i) Net heating and net increment of water vapor of the air.

The equation for the heating of the air is

$$
\frac{d}{d t} \ln \theta=\frac{1}{C_{p} T} \frac{d Q}{d t} .
$$

Accordingly,

$$
\begin{aligned}
\frac{d Q}{d t} & =C_{p} T \frac{d}{d t} \ln \theta \\
& =C_{p}\left\{\left(\frac{D T}{D t}\right)_{p=\text { const. }}+\frac{T}{\theta} \omega \theta_{p}\right\}
\end{aligned}
$$

where $d Q / d t$ is the heat added to the unit gram of air, $\theta$ is potential temperature, $C_{p}$ is specific heat under constant pressure, $T$ is absolute temperature, $\omega$ is vertical $p$ -

$$
\begin{aligned}
& \frac{1}{C_{p}} \int_{p_{0}}^{p_{1}}\left\{\int_{0}^{t_{0}}\left(\int_{0}^{J . S} \frac{d Q}{d t} d S\right) d t\right\} d p \\
& \approx \int_{p_{0}}^{p_{1}}\left\{\int^{J . S}\left(T_{\text {final }}-T_{\text {initial }}\right) d S+\int_{0}^{t_{0}}\left(\oint^{J . S} v_{n} T d s\right) d t+\frac{\bar{T}^{J . S} \cdot}{\theta} \int_{0}^{t_{0}}\left(\int^{J . S} \omega \theta_{p} d S\right) d t\right\} d p
\end{aligned}
$$

where $p_{0}$ and $p_{1}$ are pressure at the surface and that at the heighest level of airmass modification respectively, J.S. indicates the Japan Sea, $t_{0}$ is the period of the cold air outburst for integration and $S$ and $s$ are the area and line element respectively. For water vapor, following equation almost conformal with equation (3) is available,

$$
\begin{aligned}
& \int_{p_{0}}^{p_{1}}\left\{\int_{0}^{t_{0}}\left(\int_{0}^{J . S} \frac{d q}{d t} d S\right) d t\right\} d p \\
\approx & \int_{p_{0}}^{p_{1}}\left\{\int^{J . S}\left(q_{\text {final }}-q_{\text {initial }}\right) d S+\int_{0}^{t_{0}}\left(\oint^{J . S} v_{n} q d s\right) d t+\int_{0}^{t_{0}}\left(\int^{J . S} \omega q_{p} d S\right) d t\right\} d p
\end{aligned}
$$

where $q$ is the mixing ratio i.e. mass in gram of water vapor per kilogram of dry air. The first terms of the right hand sides of above equations (3), (4) are not exactly estimated because of the sparce data over the sea, but as the wind direction is rather steady from the northwest, the longer is the period of time integration, the smaller are the relative magnitude of the terms in comparsion to other terms, and accordingly the more accurate becomes our computation. 
Next, for the computation of the 2nd term, we adopted geostrophic wind, because better coverage in space and time could be provided, and because geostrophic wind is not affected by local orography. Then, the second term is further modified in the actual calculation, i.e.,

$$
\begin{gathered}
\int_{0}^{t_{0}}\left(\oint^{J . s} v_{n} T d s\right) d t \approx \int_{0}^{t_{0}}\left(\oint^{J . S} v_{g n} T d s\right) d t=\int_{0}^{t_{0}}\left\{\frac{1}{f} \Delta \phi \sum_{i}\left(T_{i}{ }^{0}-T_{i}^{I}\right)\right\} d t \\
\int_{0}^{t_{0}}\left(\oint^{J . S} v_{n} q d s\right) d t \approx \int_{0}^{t_{0}}\left\{\frac{1}{f} \Delta \phi \sum_{i}\left(q_{i}{ }^{0}-q_{i}{ }^{I}\right)\right\} d t
\end{gathered}
$$

where $v_{n}$ and $v_{g n}$ are the components of observed and geostrophic wind vector normal to the boundary and points outward respectively, $\Delta \phi$ is the interval of contour height, $T_{i}{ }^{0}$ and $q_{i}$ are the mean absolute temperature and mixing ratio of water vapor among two contour lines on the outgoing boundary respectively and $T_{i}{ }^{1}$ and $q_{i}{ }^{r}$ are those on the incoming boundary (refer Fig. 10). This method is based upon the principle that the airmass which flows between two contour lines is constant assuming geostrophic wind relation, and seems to be considerably

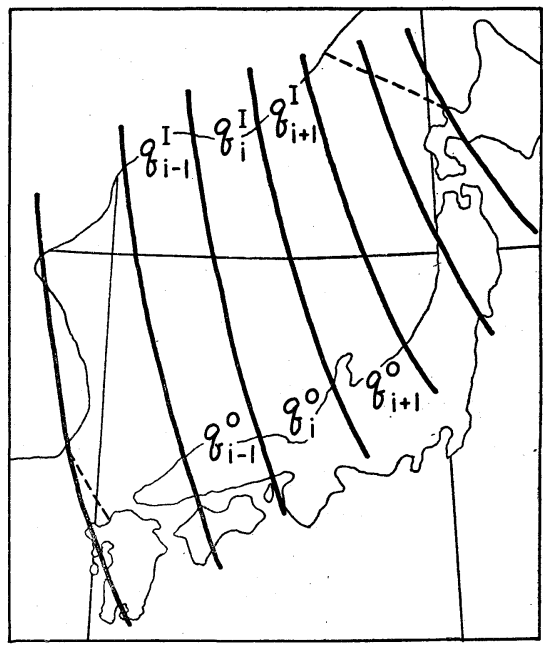

Fig. 10. Schematic figure explaining the method of computation.

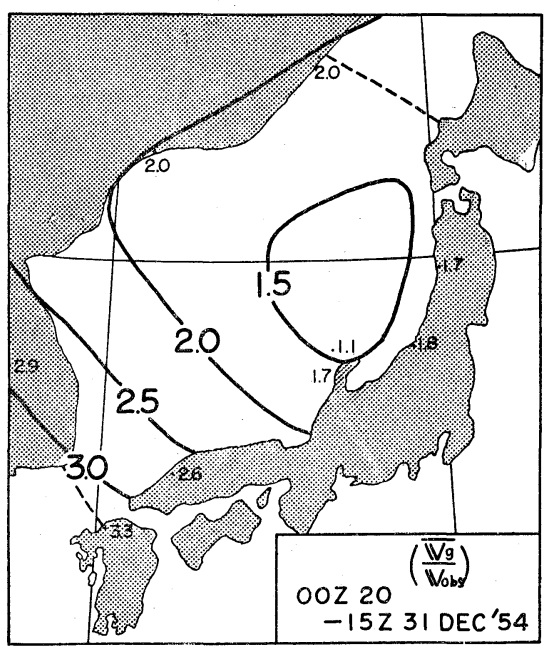

Fig. 11. Mean horizontal distribution of the radio $V_{\text {geostrophic }} / V_{\text {observed }}$.

accurate in the upper air. However, at the surface this approximation is not applicable. In Fig. 11, the horizontal distribution of mean ratio $\left|\overline{\boldsymbol{V}_{\text {geostrophic }}}\right| /\left|\overline{\boldsymbol{V}_{\text {observed }}}\right|$ at the end of Dec. '54 is shown, where we notice that the magnitude of geostrophic wind velocity is twice as large as observed wind velocity at the surface. Therefore, we assumed that the surface flux is one half of the value of horizontal net flux divergence of enthalpy and water vapor computed by geostrophic approximation.

Next, concerning the third terms i.e., vertical transport of entropy and water vapor, following approximation was adopted.

$$
\begin{aligned}
& \frac{T}{\theta} \int_{0}^{t_{0}}\left(\int^{J . S} \omega \theta_{p} d S\right) d t \\
& \approx T \overline{(\ln \theta)_{p}^{J S}} \int_{0}^{t_{0}}\left\{\int^{J . S}\left(\int_{p_{0}}^{p_{1}}(-\nabla \cdot \boldsymbol{V}) d p\right) d S\right\} d t=-T \overline{(\ln \theta)} \int_{p_{0}}^{J . S}\left\{\oint^{p_{1}}\left(\int_{0}^{t_{0}} \boldsymbol{V} d t\right)_{n} d s\right\} d p \\
& \quad \int_{0}^{t_{0}}\left(\int^{J . S} \omega q_{p} d S\right) d t \approx-\bar{q}_{p}^{J . S} \int_{p_{0}}^{p_{1}}\left\{\oint^{J . S}\left(\int_{0}^{t_{0}} \boldsymbol{V} d t\right)_{n} d s\right\} d p
\end{aligned}
$$

According to these equations, we integrated the wind vectors at the surrounding observation stations throughout the period, computed the mean divergences at various levels and obtained the vertical distribution of mean vertical velocity over the Japan Sea. Explaining in more 
detail, as instantaneous values of divergence are very fluctuative and seem to be errorneous, we gave up the estimation of the influence of smaller eddies. By adopting such an integrated wind vector we expected the nonsystematic errors which are contained in wind observations cancel with each other. In

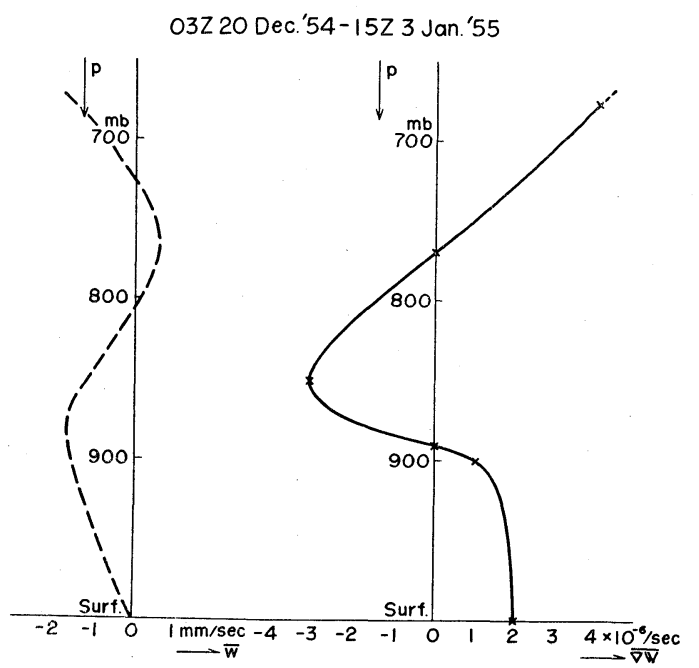

Fig. 12. Vertical distribution of mean divergence and of vertical velocity in $\mathrm{mm} / \mathrm{sec}$.

Fig. 12, both the vertical distribution of divergence and that of vertical velocity are shown, where we notice that generally divergence predominates, but at about $850 \mathrm{mb}$ level i.e., at lower half of cumulus cloud on the west coast of Japan, convergence region appears, namely the downward current expected in such a situation is very weak. This is unlike to the case of cold air outburst over the continent (20), and suggests that the intense airmass modification may affect the large scale vertical velocity to some degree.

Here, brief mention must be made how the estimation is made at $500 \mathrm{mb}$ level. At this level, the data of water vapor is very sparse, because Japanese radiosonde is designed to stop to send the signal of humidity when the temperature falls down to $-30^{\circ} \mathrm{C}$. Furthermore, the wind data at $500 \mathrm{mb}$ level are much more sparce than those at lower levels. Therefore, by use of information that the height of inversion base hardly exceeds $500 \mathrm{mb}$ level (refer Fig. 5a), we assumed that the modification due to vertial eddy transport does not take place at this level.
The charts used for above computations are as follows:

1. Surface weather map of the Far East published by Japan Meteorological Agency;

2. Upper air chart published by Japan Meteorological Agency;

3. Original upper air chart made by Japan Meteorological Agency.

The time integration of various quantities above-mentioned were made by using the upper air charts at $03 \mathrm{GCT}$ and $15 \mathrm{GCT}$ and surface charts at $00 \mathrm{GCT}$ and $12 \mathrm{GCT}$.

ii) Heating or cooling due to the long wave radiation

The calculation of the long wave radiation were performed by use of radiation chart

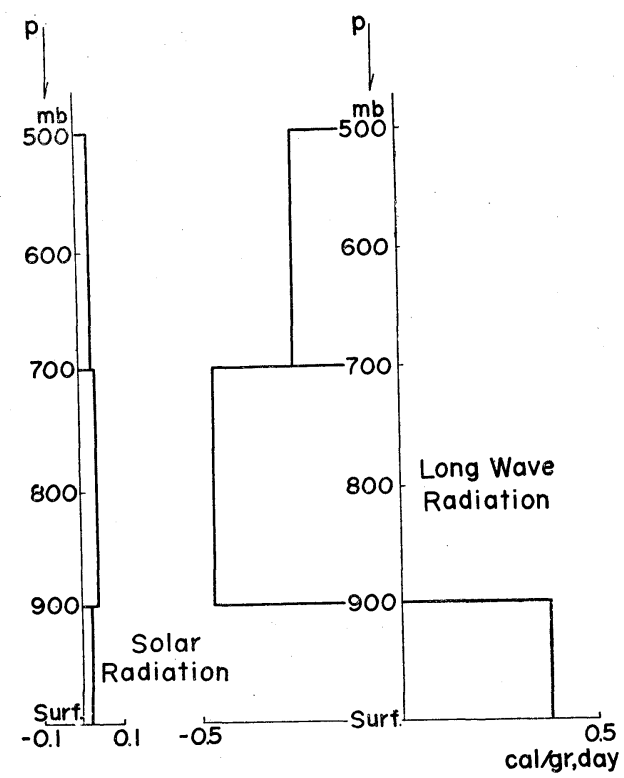

Fig. 13. Mean vertical distribution of heating and cooling due to long wave radiation and that of heating due to the absorption of incoming solar radiation (03GCT 20 Dec. '54-15GCT 3 Jan. '55).

proposed by Yamamoto(18). Strictly speaking, the cooling for each day should be computed, and then daily value should then be averaged. However, in this case for the sake of convenience, the mean vertical distributions of potential temperature and that of water vapor in Fig. 6a, b were adopted instead of daily values. As for cloud, also the mean vertical distribution of cloudiness in Fig. $5 \mathrm{~b}$ was used. 
By use of this scheme, computation was made for the radiosonde observation stations surrounding the Japan Sea. Then interpolating these values we obtained the vertical distribution of heating or cooling due to the long wave radiation. Here, as the surface

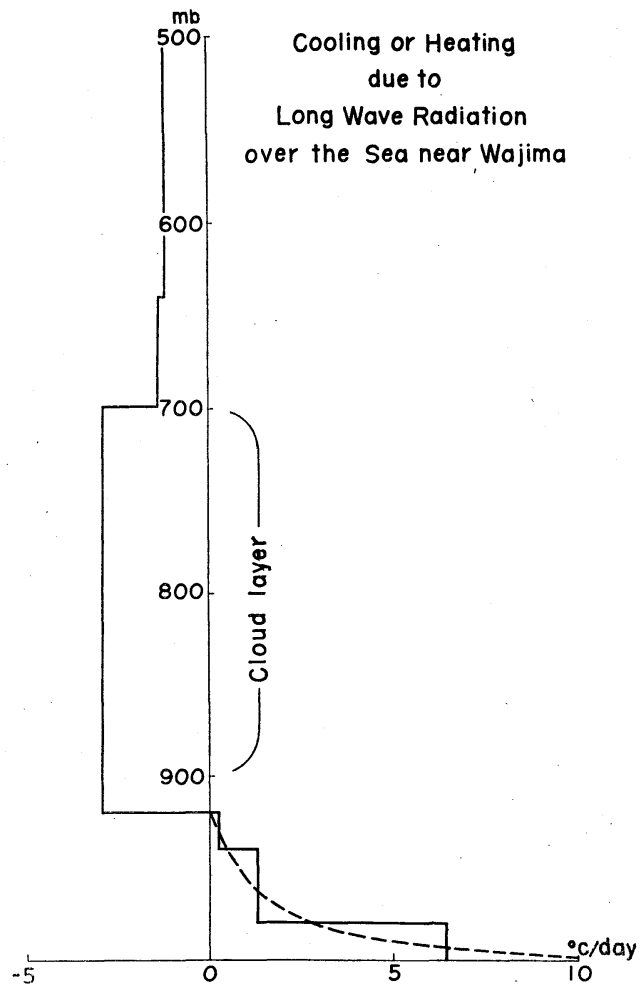

Fig, 14. The mean vertical distribution of temperature change above the sea surface near Wajima caused by long wave radiation (03GCT 20 Dec. '54-15GCT 3 Jan. '55).

temperature, we adopted the water surface temperature off the coast, instead of soil temperature at the radiosonde observation stations. Fig. 13 shows the mean vertical distribution of cooling computed in such a way. The heating in the lowest layer is chiefly due to the large temperature difference between the sea and the atmosphere (refer Fig. 8a).

In order to study the effect of high water surface temperature in more detail, we calculated the heating at Wajima deviding the lower troposphere into thinner layers, which is shown in Fig. 14. The remarkable heating in the lowest layer suggests the excita- tion of convection in the lowest layer of the atmosphere by the long wave radiation from the sea surface.

\section{iii) Heating due to incoming solar radia- tion}

The mechanism of absorption of insolation by the atmosphere is very complicated and the exact solution of the problem is still lacking. Recently Yamamoto and Onishi(19) have given the convenient nomogram to calculate the absorption in the sky. Using their scheme, we integrated the amount of heating due to incoming solar radiation with respect to the various hour angle of the sun for each radiosonde observation station and interpolating these values, we obtained the vertical distribution of mean heating over the Japan Sea during the selected period as shown in Fig. 13*. As the cloud albedo, referring the values obtained by Neuburger ${ }^{(10)}$ and Aldlich(1), we adopted $78 \%$ for cumulus or cumulonimbus and $65 \%$ for altocumulus or stratocumulus, and at the surface, albedo of water instead of that of earth was adopted. Concerning the transmission inside the cloud, the table made by Hewson ${ }^{(5)}$ is available. In the computations, it was kept in mind that radiation

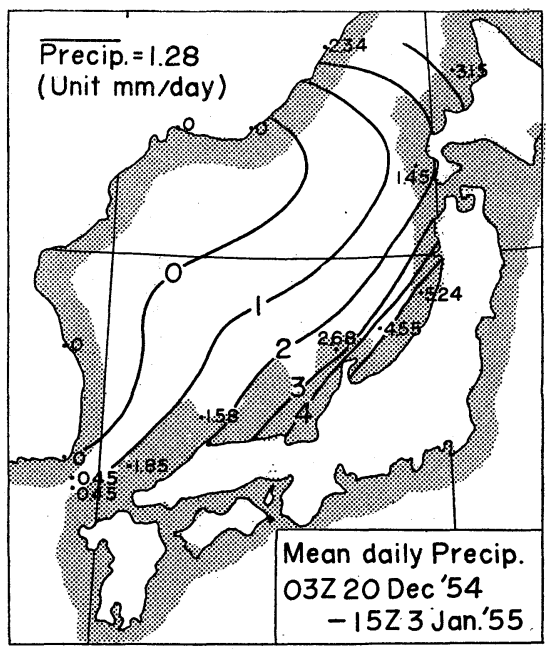

Fig. 15. Mean horizontal distribution of daily precipitation over Japan Sea.

* In this computations, the vertical distributions of mean temperature, water vapor and cloud given in $\$ 4$ were also used instead of daily distributions. 
becomes diffuse after passing through the cloud.

\section{iv) Estimation of the amount of heat re- leased by the condensation}

The accurate estimation of the amount of precipitation over the sea is a very difficult task because of sparce data. However, over the Japan Sea during this selected period of cold air outburst, the amount of rainfall is comparatively small. Besides, off the coast of "Back" Japan there are many islands i.e., Yagishirijima, Okujirijima (Inahomisaki), Tobishima, Sado (Aikawa), Hekurajima, Okinoshima (Saigo) and Tsushima (Susuna), etc.* Therefore it was possible to decide the distribution of rainfall which is useful for the present purpose. In Fig. 15, the mean distri-

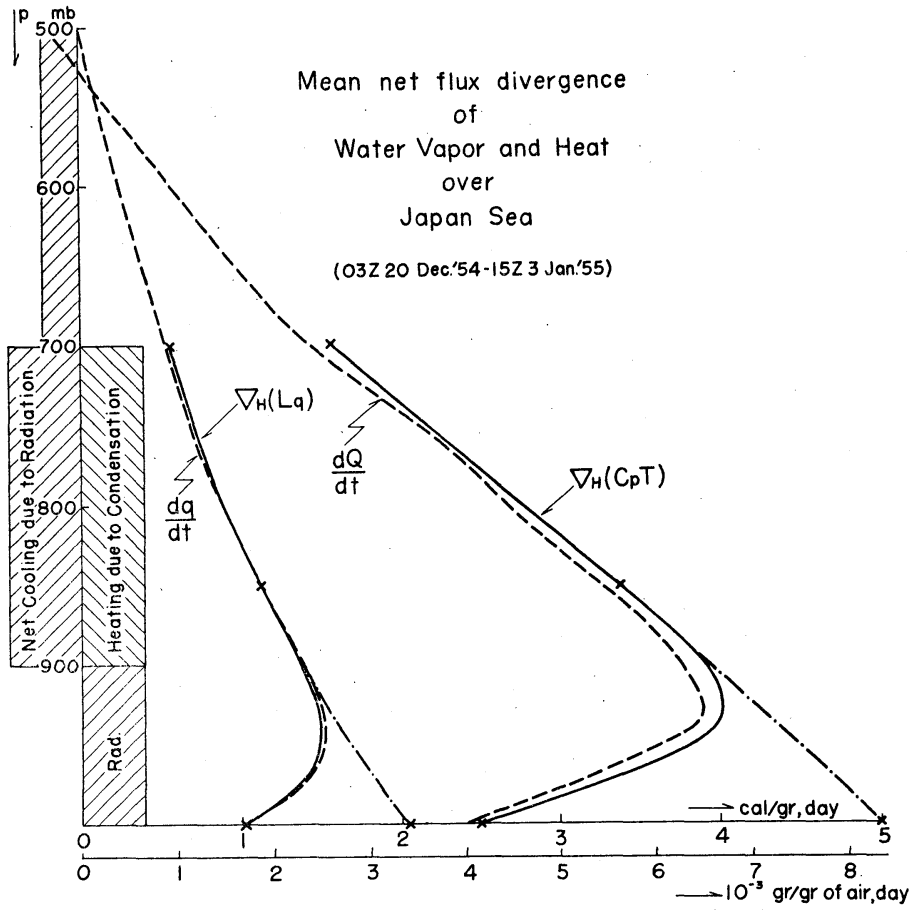

Fig. 16. Solid lines shows the mean vertical distribution of horizon tal net flux divergence of enthalpy and water vapor and dotted lines show that of individual increase of sensible and latent energy (cal/gr. of air, day). Heating and cooling due to radiation and condensation are also shown in the same unit $03 \mathrm{GCT}$ 20 Dec. '54-15 GCT 3 Jan. '55).

* Unfortunately, the amount of rainfall observed at Ulungdo which is in the southwestern part of the Japan Sea was not useful for the present purpose because of the intense snowfall due to the high mountain in the island. bution of the amount of precipitation per day is shown, which indicates that the most of precipitation concentrates to coast of "Back" Japan and precipitation hardly took place near the coast of continent during this period of cold air outburst. Accordingly, the mean amount is as little as $1.3 \mathrm{~mm} /$ day.

\section{Discussion of results}

The final results obtained by the computations in the foregoing sections are shown in Fig. 16, where solid lines show the vertical distribution of horizontal divergence of both enthalpy and latent energy, and dotted lines are the individual increases of these quantities in the air. In the same place, the mean amount of heat released by condensation and net cooling or heating due to radiation with respect to several layers** are shown, and the integrated values of these quantities from surface up to $500 \mathrm{mb}$ level are tabulated in Table 2. Here, we

Table 2. Heat budget of the lower half of troposphere over the Japan Sea during the period of typical cold air outburst.

\begin{tabular}{l|l}
\hline & \multicolumn{1}{|c}{ ly/day } \\
\hline $\begin{array}{l}\text { Heat supplied from } \\
\text { the sea surface }\end{array}$ & 1030 \\
$\begin{array}{l}\text { Latent heat suppli- } \\
\text { ed from the sea }\end{array}$ & $450(7.5 \mathrm{~mm} /$ day $)$ \\
surface & $\begin{array}{l}\text { Net cooling due to } \\
\text { radiation }\end{array}$ \\
$\begin{array}{l}\text { Heating due to } \\
\text { condensation }\end{array}$ & $77(1.3 \mathrm{~mm} /$ day $)$ \\
\hline
\end{tabular}

notice that the amount of supplied heat energy is extremely large during this period i.e., about $1000 \mathrm{ly} /$ day which is much larger than the amount of net cooling due to radiation or heating due to condensation, and this supplied heat energy is 2.3 times as much as supplied latent heat energy.

** The layer was divided according to the cloud distribution over "Back" Japan in Fig. 5b. 
On the other hand, according to the scheme after Jacobs, the expected amount of the evaporation was computed by using the following equation,

$$
E=0.23 V_{a}\left(q_{s}-q_{a}\right)
$$

where $E$ is the amount of evaporation in $\mathrm{mm} /$ day, $V_{a}$ is the wind velocity at the height $a$ (Fig. 3), and $q_{s}$ and $q_{a}$ are the saturated mixing ratio of water vapor for the water surface temperature and mixing ratio of the surface air respectively (refer Fig. $8 \mathrm{~b})$. The distribution of evaporation thus computed is shown is Fig. 17 and the

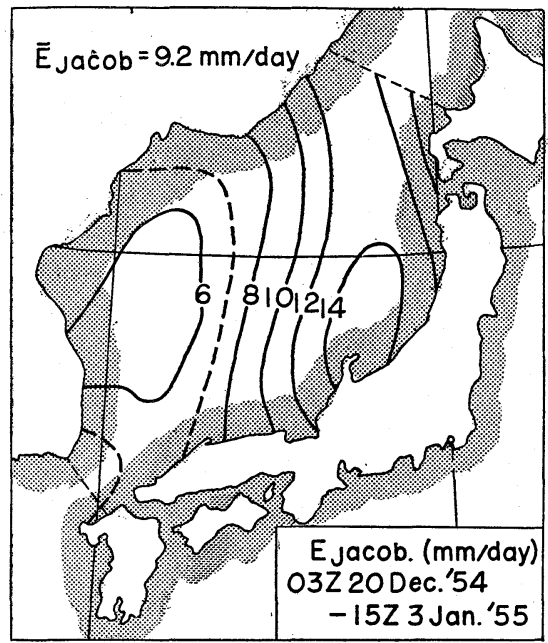

Fig. 17. Distribution of evaporation computed by Jacobs' scheme in mm/day (03 GCT 20 Dec. '5415 GCT 3 Jan. '55).

mean amount is about $9.2 \mathrm{~mm} /$ day and is comparable with the value obtained by the above computation $(7.5 \mathrm{~mm} /$ day $)$.

In order to testify this scheme in more detail, we selected several period during which remarkable cyclones did not pass over the Japan Sea and accordingly the amount of precipitation was comparatively small. The mean situations of these periods are shown briefly in Table 3. For these periods, computation by both upper air observation and by Jacobs' scheme was performed and the results are shown in Fig. 18, where we notice that the linearity exists between them to some degree, but the former is a little smaller than the latter and, moreover, this tendency is remarkable at the end of Feb-
Table 3. Brief description of the surface situations over the Japan Sea during several periods selected for present study, where $\overline{\Delta T}$ and $\Delta \bar{q}$ are the mean air-sea difference of temperature and mixing ratic of water vapor respectively.

\begin{tabular}{|c|c|c|c|c|c|}
\hline & $\begin{array}{c}\bar{V}(\mathrm{~m} / \mathrm{s}) \\
V_{\min } \sim \\
V_{\max }\end{array}$ & $\begin{array}{l}\overline{\Delta T}\left({ }^{\circ} \mathrm{C}\right) \\
\left(\Delta T_{\min }\right. \\
\left.\sim \widetilde{T_{\max }}\right)\end{array}$ & $\left(\begin{array}{c}\overline{\Delta q} \mathrm{gr} / \mathrm{kg} \\
\left(\Delta q_{\mathrm{min}}\right. \\
\left.\widetilde{\Delta q_{\max }}\right)\end{array}\right.$ & $\begin{array}{c}\overline{\boldsymbol{E}}_{\mathrm{Jacobs}} \\
\text { (mm/ } \\
\text { day) }\end{array}$ & $\begin{array}{c}\bar{E}_{\text {obs }} \\
(\mathrm{mm} / \\
\text { day })\end{array}$ \\
\hline $\begin{array}{c}\text { 03GCT 20 Dec. } \\
\text { '54-15GCT } \\
3 \text { Jan. '55 }\end{array}$ & $\begin{array}{c}7.8 \\
(3-15)\end{array}$ & $\begin{array}{l}12.6 \\
(11-16)\end{array}$ & $\begin{array}{c}5.3 \\
(4-9)\end{array}$ & 9.2 & 7.5 \\
\hline $\begin{array}{l}\text { 03 GCT } 5 \text { Jan. } \\
\text { 15GCT } 8 \text { Jan. } \\
\text { '55 }\end{array}$ & $\begin{array}{l}7.8 \\
(3-12)\end{array}$ & $\begin{array}{l}11.9 \\
(9-15)\end{array}$ & $\begin{array}{c}4.9 \\
(3-9)\end{array}$ & 8.7 & 5.2 \\
\hline $\begin{array}{c}\text { 03GCT 10 Jan. } \\
\text { 15GCT } 13 \text { Jan. } \\
\text { '55 }\end{array}$ & $\begin{array}{l}7.1 \\
(2-11)\end{array}$ & $\begin{array}{l}11.3 \\
(10-14)\end{array}$ & $\begin{array}{c}4.9 \\
(3-8)\end{array}$ & 7.9 & 3.6 \\
\hline $\begin{array}{l}\text { 03GCT22Feb. } \\
\text { 03GCT26 Feb. } \\
\text { '55 }\end{array}$ & $\begin{array}{c}5.7 \\
(3-9)\end{array}$ & $\begin{array}{c}4.7 \\
(1-10)\end{array}$ & $\begin{array}{c}3.3 \\
(2-5)\end{array}$ & 4.7 & 2.0 \\
\hline
\end{tabular}

ruary. As reference, the experimental lines which are obtained by Sverdrup ${ }^{(14)}$ both for rough and smooth surface are also drawn in the same figure. Here, in spite of the strong wind velocity (refer Fig. 3), the plotted points are rather near the line for smooth surface than that for rough surface. This tendency seems to be due to various reasons. For example, the wind observation used here were made by the observation station on is-

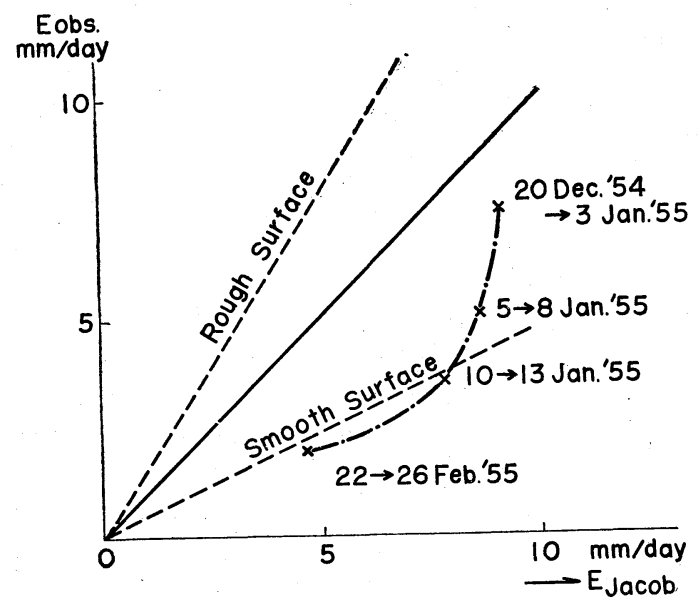

Fig. 18. The mean daily amount of evaporation obtained in the present work against that obtained from Jacobs' scheme. Dotted lines show the amount of evaporation both for smooth and rough surface expected from the empirical formula obtained by Sverdrup. 
lands or the ones at the coast of the continent. Therefore the anemometer level is usually higher than the level of ship-deck (refer Table 1). Furthermore, the wind velocities at the coast or in islands may be different from that over sea. Accordingly it is not exact to compare our results directly with the one obtained by Jacobs' scheme. However, present results may give some information for the estimation of evaporation over the Japan Sea.

The amounts of heat energy supplied from the sea during these periods are also computed. For example, the mean amount of the exchange of heat energy from $03 \mathrm{GCT} 10$ to $15 \mathrm{GCT}$ 13 Jan. '55 is about 400 ly/day and it decreases to less than 100 ly/day at the end of February. Therefore it must be kept in mind that the amount of the heat exchange of $1000 \mathrm{ly} /$ day takes place in the typical situation of cold air outburst and is considerably larger than the climatological value during winter. As reference, the mean heating over the Japan Sea during winter after Miyazaki ${ }^{(8)}$ is about $250 \mathrm{ly} /$ day. On the other hand, Winston ${ }^{(17)}$ obtained the heating $1000-20001 \mathrm{l} /$ day in the typical situation of the outburst of cold arctic air over the Gulf of Alaska.

Concerning the ratio at which heat and water vapor are transported across the lower and upper surfaces of volume of air above a body of water, Bowen has determind that the ratio $R$ of the heat loss by conductions to that by evaporation can be obtained by means of the following formula

$$
R=0.405 \times \frac{t_{w}-t_{a}}{q_{w}-q_{a}}
$$

where $t_{w}$ and $t_{a}$ are the temperature in degree of centigrade of the water and air respective1y. The fundamental assumption which is adopted for the derivation of above equation (10) is that the eddy conductivity of heat is equal to that of water vapor. As for the applicability of this assumption, Sverdrup (14) has stated, "the successful application of the theory of turbulence to the problem of airmass transformation suggest that there exists no large difference in the process by which heat and water vapor are diffused." Jacobs, along this line, computed the distribution of Bowen's ratio for various oceans, and obtain- ed the exchange of sensible heat at the sea surface based on his estimation of exchange of latent heat. Then, the present author also calculated the distribution of Bowen's ratio in the same way, and as shown in Fig. 19, found that it is nearly equal to unity on the Japan Sea. The ratio between these two quantities which was obtained above is 2.3 and is remarkably different from the ratio computed by use of equation (10).

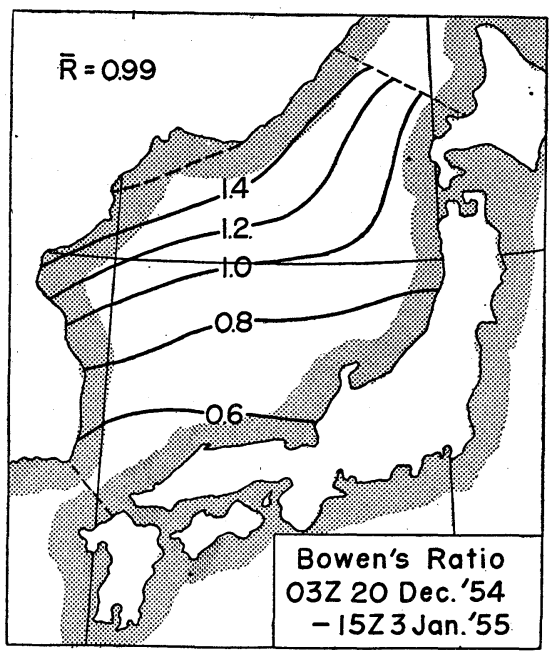

Fig. 19. Mean horizontal distribution of Bowen's ratio expected from mixing length theory over the Japan Sea.

Of course, distributions of the air temperature and water vapor used for the present computation were determined by observations at coast or those on small islands, so they may differ slightly from those at the ship-deck level. However, in the present case the airsea temperature difference is very large and accordingly they seem to give us acceptable ratio. The reason why so much sensible heat compared with latent heat is supplied to the atmosphere in our case seems to be chiefly due to the intense convection, which may take place even under the ship-decklevel in the unstable situation of cold air outburst over the sea. Namely, as the primaly reason of convective upward current is the non-uniform distribution of temperature, the correlation between the eddy vertical velocity and temperature fluctuation may far exceeds that between the eddy vertical velocity and the fluctuation of mixing ratio 
of water vapor in the typical unstable situation, because the fluctuation of temperature is not always similar to that of water vapor content. As for this kind of problem Priestry and Swinbank ${ }^{(11)}$ has already emphasized that under unstable condition the mechanism of vertical transport may be different with respect to various quantities, and Swinbank ${ }^{(13)}$, in his measurement on flat pasture land, showed that the diffusion coefficient of heat energy is about 1.5 times as large as that of water vapor in the unstable atmosphere at the height of $2.5 \mathrm{~m}$. Over the ocean due to the difficulty of measurement, we can hardly find out the reliable results for this problem. Furthermore there may be other factors which influences the energy exchange at the air-sea boundary than those at the air-land boundary, i.e. the effects of spray and the wave of sea water. It is also doubtful whether temperature and the mixing ratio of water vapor in the air which contact with sea water, are equal to temperature of sea water and its saturated mixing ratio respectively in the transient situation of cold air outburst and on the rapidly changing sea surface, or not. Therefore, we cannot make conclusive discussion about the mechanism of energy transport at the sea surface directly from present results. However, at least, we wish to emphasize that in such a typical unstable situation, the amount of energy exchange in sensible form seems to exceed much that of energy exchange in latent form, in spite of the fact that Bowen's Ratio expected from mixing length theory is nearly equal to unity over the Japan Sea.

Finally, brief comment must be made about the contribution of long wave radiation to the transport mechanism. As shown in Fig. 14, the remarkably large heating in thin layer of the air on the sea surface due to high water surface temperature may have important effect on the convection, and accordingly on the change of vertical temperature gradient near the sea surface. Therefore, it may be also possible that the vertical distribution of temperature and water vapor is not similar under the ship-deck level, though, needless to say, more detailed investigation i.e. actual measurement is necessary before such a kind of discussion is made.

\section{Conclusion and future work}

The results obtained in the foregoing sections can be summarized as follows.

i) During the period of intense outburst of polar continental air over the Japan Sea, the amount of sensible heat supplied from the sea to the atmosphere is as much as $1000 \mathrm{ly} /$ day.

ii) Therefore, in such a situation, the amount of heating or cooling due to radiation or condensation is far less than the heating due to eddy transport of heat. However, it must be remembered that the heating in the thin layer adjacent to the water surface caused by the long wave radiatian is extremely large, because of the large air-sea temperature difference which exceeds $10^{\circ} \mathrm{C}$. Therefore the long wave radiation may also play an important role for the convection and modification of airmass in the lowermost layer of the atmosphere.

iii) The ratio at which heat and water vapor supplied from the sea to the atmosphere seems to be much larger than the ratio expected from mixing length theory. This suggests that in such a typical unstable situation the mechanism of heat transport seems to be considerably different from that of water vapor transport. In more detail, the amount of the exchange of sensible heat is 2.3 times as much as that of latent heat, in spite of the fact that mean Bowen's ratio expected from mixing length theory is nearly equal to unity during this period. The vertical distribution of the individual increase of heat energy due to eddy transport seems to approach that of latent energy in the $900-700 \mathrm{mb}$ layer in which cumuli stand over the eastern part of Japan Sea if we consider the effect of condensation (refer Fig. 16).

iv) There exists linearlity to some degree between the amounts of evaporation computed by our method and the products of surface wind velocity and air-sea difference of the mixing ratio of water vapor. Studies of much more situations and the ship observations of various meteorological elments are necessary for the more detailed quantitative discussions.

As for future work, it seems to be neces- 
sary to perform the same kind of investigations for much more situations over Japan Sea over the Okhotsk Sea and over the East China Sea which are situated at different latitudes and also surrounded by upper air observation stations, and to study how the degree of modification changes or how the ratio between the sensible heat and latent energy exchange varies under different situations of the sea and the atmosphere.*

On the other hand, it may be possible that the rapid change of potential vorticity takes place in the lower layer of the troposphere during the period of the intense outburst of cold air over the Ocean. Therefore, it seems to be also necessary for the improvement of baroclinic forecast to estimate the effect of heating by the warm sea to the change of large scale distribution of potential vorticity.

\section{References}

1. Aldrich L. B. (1919): The reflecting power of cloud. Smithson. misc. Coll. 69, No. 10 .

2. Arakawa, H., Yano, S., Ifuku, I. and Yamaguchi, S. (1937): A study of monsoon by radiosonde observation of Toyama city (in Japanese). Kôkû-kishô hôkoku 2, pp. 158-181.

3. Benton, G. S. and M. A. Estoque (1954): Water-vapor transfer over the North American continent. J. Meteor. 11, pp. 462-476.

4. Bowen, I. S. (1926): The ratio of heat losses by conduction and by evaporation from any water surface. Phys. Rev. 27, pp. 779-787.

5. Hewson, E. W. (1943): The reflection, absorption and transmission of solar radiation by fog and cloud. Quart. J. roy. meteor. Soc. 69, pp. 47-62.

6. Jacobs, C. W. (1951): The energy exchange between sea and atmosphere and some of its consequences. Bull. Scrips Inst. Ocean. Univ. Cal. 6, 27-122.

7. Kurooka, H. (1957): Modification of Siberian air mass caused by flowing out over the open sea surface of northern Japan. Journ. Met. Soc. Ser. II 35, 52-59.

8. Miyazaki, M. (1949): The incoming and outgoing heat at the sea surface along the Tsushima warm current. Ocean. Mag. Tokyo, 1, pp. 103-111.

* Study of airmass modification over the Japan Sea during winter will be published soon in this Journal.

\section{Acknowledgement}

The author would like to express his hearty thanks to Prof. Syōno and Prof. Isono for their guidance and encouragement throughout the course of this study and is very much obliged to Dr. Ogura, Mr. Miyakoda and Mr. Komabayasi, Division of Meteorology, Geophysical Institute, Tokyo University, for their helpful discussions and suggestions and also to Mr. Tsuchiya, Division of Oceanography of same institute, who gave the author the effective information about the state of the Japan Sea. The author is also indebted to Dr. Wonchul, Director of Central Meteorological Observatory of Republic of Korea, who kindly sent the author the precipitation data over south Korea, and to Mr. Fujii, Marine Safty Agency, who kindly arranged the necessary data observed at light houses.

9. Murakami, T. (1957): On the seasonal variation of vertical velocity and atmospheric heat sources over the Far East from spring to summer. Papers in Meteor. and Geophys. 7, pp. 358-376.

10. Neiburger, M. (1949): Reflection, absorption and transmission of solar radiation by stratus cloud. J. Meteor. 6, pp. 98-104.

11. Priestly, C. H. B. and Swinbank, W. C. (1947): Vertical transport of heat by turbulence in the atmosphere. Proc. roy. Soc. (A) 189, pp. 543-561.

12. Riehl, H., T. C. Yeh, J. S. Malkus and N. E. La Seur (1951): The north-east trade of the Pacific Ocean. Quart. J. roy. meteor. Soc. 77, pp. 598-626.

13. Swinbank, W. C. (1955): Eddy transport in the atmosphere. Australia, Commonwealth sci. ind. Res. Organization, Div. Meteor. Phys. Tech. Paper 2.

14. Sverdrup, H. U. (1946): The humidity gradient over the sea surface. J. Meteor. 3, pp. 1-8.

15. Takahashi, K. (1940): On the modification of cold airmass travelling over Japan Sea (in Japanese). J. Meteor. Soc. Japan 18, pp. 77-80.

16. Wexler, H. (1944): Determination of normal region of heating and cooling in the atmosphere by means of meteorological data. J. Meteor. 1, pp. 23-28.

17. Winston, J. (1955): Physical aspect of rapid cyclogenesis in the Gulf of Alaska. Tellus. 7, pp. 481-500. 
18. Yamamoto, G. (1952): On a radiation chart. Sci. Rep. Tohoku Univ. Ser. V Geophys. 4, pp. 9-23.

19. Yamamoto, G. and Onishi, G. (1952): Absorption of solar radiation by water vapor in the atmosphere. J. Meteor. 9, p. 415.

20. Palmén, E. and C. W. Newton (1951): On the three-dimensional motion in an outbreak of polar air. J. Meteor. 8, pp. 25-39. 